НАЗАРОВ Владимир Павлович - кандидат политических наук; советник секретаря Совета безопасности РФ (103132, Россия, г. Москва, Ипатьевский пер., 4-10; Vlnazarov1950@gmail.com) АФИНОГЕНОВ Дмитрий Александрович - доктор политических наук, профессор Института права и национальной безопасности Российской академии народного хозяйства и государственной службы при Президенте РФ (119571, Россия, г. Москва, пр-кт Вернадского, 84, корп. 6; afinogenov_d@inbox.ru)

\title{
ПРОБЛЕМЫ РАЗВИТИЯ ОБЩЕЙ ТЕОРИИ НАЦИОНАЛЬНОЙ БЕЗОПАСНОСТИ В КОНТЕКСТЕ КОРРЕКТИРОВКИ СТРАТЕГИИ НАЦИОНАЛЬНОЙ БЕЗОПАСНОСТИ РОССИЙСКОЙ ФЕДЕРАЦИИ
}

\begin{abstract}
Аннотация. В статье рассматриваются проблемы развития теории национальной безопасности Российской Федерации в новых геополитических и экономических условиях. Авторы дают предметный анализ изменения теоретических взглядов на понятие «национальная безопасность», предлагают новый подход к содержанию данного термина. В статье обосновывается роль и место стратегического планирования как важнейшего инструмента обеспечения национальной безопасности, сформулированы рекомендации по оптимизации и совершенствованию этого процесса. Авторы дают рекомендации по корректировке Стратегии национальной безопасности Российской Федерации.

Ключевые слова: национальная безопасность, социально-экономическое развитие, стратегическое планирование, стратегические национальные приоритеты, целеуказание, стратегия
\end{abstract}

B последнее время вопросам повышения эффективности государственного управления в сфере социально-экономического развития и обеспечения национальной безопасности Российской Федерации уделяется повышенное внимание. Эта тема как важнейший компонент стратегического планирования отчетливо позиционируется в ежегодных посланиях президента РФ Федеральному собранию РФ, вызывает оживленные дискуссии в научной среде.

Такой интерес не случаен, т.к. реалии сегодняшнего дня ставят перед Россией сложнейшие проблемы развития и обеспечения национальной безопасности в системе новых глобальных вызовов и угроз, требуют выверенной и научно обоснованной методологии и опоры на стратегическое планирование при проведении государственной политики обеспечения национальной безопасности и устойчивого социально-экономического развития.

Не вызывает сомнения, что вопросы обеспечения национальной безопасности сегодня и на длительную перспективу являются центральными и стратегически значимыми в повестке дня развития страны. За прошедшие с образования новой России годы на этом направлении проведена значительная работа.

Сформулирована достаточно объемная система документов стратегического планирования, включающая в себя базовые документы стратегического целеполагания на федеральном уровне (Стратегический прогноз Российской Федерации, Стратегия национальной безопасности Российской Федерации), документы стратегического целеполагания на региональном уровне и значительный пакет программно-плановых документов, включая государственные программы РФ.

Принята новая редакция федерального закона «О безопасности», федеральный закон № 172-Ф3 «О стратегическом планировании в Российской 
Федерации», ряд иных федеральных законов, а также указы и решения президента РФ в сфере обеспечения национальной безопасности и стратегического планирования, соответствующие постановления правительства РФ.

Вместе с тем ряд ключевых для общей теории национальной безопасности вопросов остались недостаточно проработанными. Прежде всего, это касается понимания термина «национальная безопасность», который носит принципиальный характер и от которого во многом зависит сам вектор политики обеспечения национальной безопасности. Как отмечает видный специалист в области национальной безопасности А.А. Прохожев, при разумном подходе к решению любой проблемы необходима прежде всего глубоко проработанная, научно обоснованная понятийная база [Общая теория... 2005: 14].

Сегодня вся конструкция системы концептуальных взглядов в области национальной безопасности России и в сфере ее социально-экономического развития базируется на неких общих постулатах теории национальной безопасности, определяющей в целом суть и содержание государственной политики РФ в этой сфере. В чем же суть этих постулатов?

Главный из них заключается в том, что национальная безопасность РФ есть состояние защищенности личности, общества и государства от внутренних и внешних угроз, при котором обеспечиваются реализация конституционных прав и свобод граждан РФ (далее - граждане), достойные качество и уровень их жизни, суверенитет, независимость, государственная и территориальная целостность, устойчивое социально-экономическое развитие Российской Федерации ${ }^{1}$.

Этот термин, приведенный в Стратегии национальной безопасности, своими корнями уходит в середину 90-х гг. прошлого века - в традиции, заложенные законом «О безопасности» 1992 г. и научно-практическими взглядами, которые легли в основу трактовки феномена «национальная безопасность».

В частности, в первой Концепции национальной безопасности Российской Федерации, введенной указом Президента РФ от 17 декабря 1997 г. N 1300, термин «национальная безопасность» не был определен. Однако сущностное значение термина «безопасность» было дано еще в первом российском законе «О безопасности» 1992 г., в котором национальная безопасность определялась как защищенность национальных интересов от внутренних и внешних угроз 2 . Именно с таких позиций в Концепции рассматривались вопросы безопасности, именно такое определение безопасности как состояния защищенности от угроз можно проследить по работам российских исследователей того времени В.С. Пирумова, В.В. Серебрянникова, Л.И. Шершнева, С.В. Степашина.

В Концепции национальной безопасности Российской Федерации в редакции указа Президента РФ от 10.01.2000 N 24 уже дается определение: «под национальной безопасностью Российской Федерации понимается безопасность ее многонационального народа как носителя суверенитета и единственного источника власти в Российской Федерации» ${ }^{3}$. Вместе с тем и в начале нулевых годов российская политическая наука рассматривала термин «безопасность многонационального народа» также только с точки зрения защиты от угроз.

\footnotetext{
1 Указ Президента Российской Федерации от 31 декабря 2015 года N 683 «О Стратегии национальной безопасности Российской Федерации». Доступ: http://www.consultant.ru/document/ cons doc LAW 191669/ (проверено 21.01.2020).

2 Закон РФ «О безопасности». - Ведомости Съезда народных депутатов и Верховного Совета Российской Федерации. 1992. № 15. Ст. 669 (с изм. и доп. от 25.12.1992, 24.12.1993, 25.07.2002, 07.03.2005, 25.07.2006, 02.03.2007, 26.06.2008) (утратил силу).

3 Указ Президента РФ от 10.01.2000 N 24 «О Концепции национальной безопасности Российской Федерации» (утратил силу).
} 
В частности, А.В. Возжеников считал, что национальная безопасность - это «состояние защищенности жизненно важных интересов личности, общества и государства во всех сферах их жизнедеятельности от внутренних и внешних опасностей и угроз, характеризующееся таким положением страны, при котором обеспечивается ее целостность и внутренняя стабильность, суверенное... развитие, возможность выступать самостоятельным и полноправным субъектом международных отношений» [Возжеников 2000: 45].

Закрепление такого подхода в теории национальной безопасности и политической практике следует отнести уже к началу нулевых годов, когда вышла в свет серия работ А.А. Прохожева и В.Л. Манилова.

В частности, в 2005 г. в учебнике для вузов под общей редакцией А.А. Прохожева впервые были даны понятия объекта и предмета национальной безопасности; понятие «безопасность» рассматривалось как сложное многогранное социальное явление, имеющее конкретно-исторический характер и тесно связанное со всеми формами и направлениями взаимодействия в системе «природа - человек - общество», и отмечалось, что сущностью национальной безопасности является защищенность жизненно важных интересов личности, общества и государства в различных сферах жизнедеятельности от внутренних и внешних угроз, обеспечивающая устойчивое поступательное развитие страны [Общая теория... 2005: 14].

Другие авторы, например В.Л. Манилов, характеризуют национальную безопасность как систему, составными элементами которой являются угрозы, интересы и факторы воздействия на них, а также методы обеспечения национальной безопасности [Манилов 1995: 17].

Можно и далее перечислять различные подходы к пониманию сущности и сути этого феномена, однако общим является то, что он исходил, прежде всего, из политики реагирования на возникающие угрозы и вызовы и не отражал потребности комплексного стратегического целеполагания, охватывающего сферу как социально-экономического развития, так и обеспечения национальной безопасности.

В то же время следует признать, что в период конца 1990-х - начала нулевых годов термин «защищенность», вероятно, наиболее верно отражал тот спектр возможностей России, которыми она располагала для решения своих сложнейших задач. В то время в стране был практически утрачен институт перспективного стратегического планирования, в государственном управлении отсутствовал цельный и комплексный подход к выбору и реализации стратегических целей, процветал правовой нигилизм. Во многих субъектах РФ активно шел процесс сращивания власти с крупным бизнесом и криминальными структурами. Стремительно нарастали национализм и сепаратизм. Активно, по худшему сценарию, шли процессы социального расслоения общества, усиливались социальная стратификация и региональные диспропорции.

Поэтому рассмотрение термина «национальная безопасность» с позиций защищенности в политической практике преследовало прежде всего цель достижения социально-политической стабильности и стратегической устойчивости страны по отношению к вызовам и угрозам, т.к. перед Россией прежде всего стояла задача выживания после той национальной катастрофы, которую российское общество и государство пережили в 90 -е гг. XX в. Главное было суметь оперативно реагировать на внешние и внутренние угрозы и вызовы, не допустить развала государственности. И в этой связи парадигма «состояние защищенности» применительно к обеспечению национальной безопасности была в этот период наиболее оправданной.

Вторым достаточно устойчивым постулатом, имеющим применение и в со- 
временной теории национальной безопасности, является положение о том, что национальные интересы России - это совокупность интересов личности, общества и государства в экономической, внутриполитической, социальной, международной, информационной, военной, пограничной, экологической и других сферах ${ }^{1}$. Основа для такого понимания также была заложена еще в 1992 г. федеральным законом «О безопасности», где ст. 1 гласит, что «жизненно важные интересы - совокупность потребностей, удовлетворение которых надежно обеспечивает существование и возможности прогрессивного развития личности, общества и государства».

В последующем федеральный закон «О безопасности» № 380-Ф3 от 15 декабря 2010 г. определил понятие «национальная безопасность» как «содержание деятельности по обеспечению безопасности государства, общественной безопасности, экологической безопасности, безопасности личности, иных видов безопасности, предусмотренных законодательством Российской Федерации (далее - безопасность, национальная безопасность)» ${ }^{2}$. Однако такая трактовка не в полной мере коррелирует с положениями Стратегии национальной безопасности в редакции указа Президента РФ от 31 декабря 2015 г. N 683 «О Стратегии национальной безопасности Российской Федерации».

Именно на этих двух важнейших постулатах до сих пор базируется все здание общей теории национальной безопасности Российской Федерации. Давайте рассмотрим, насколько это целесообразно и оправданно в наше время.

Прежде всего, надо признать, что сегодня в российской политической науке нет стройного и выверенного подхода к определению сути и содержания феномена «национальная безопасность». Долгое время в нашей стране проблема обеспечения национальной безопасности рассматривалась исключительно с точки зрения задействования силового компонента и преимущественно в контексте противодействия внешним угрозам [Сергунин 2012].

Однако Россия и мир стремительно меняются, и сегодня концептуально определенный подход к обеспечению национальной безопасности исключительно через «защищенность» не в полной мере отвечает современной парадигме политики в области обеспечения безопасности - «безопасность через устойчивое развитие», что подразумевает неразрывную взаимосвязь и взаимозависимость задач обеспечения национальной безопасности и социально-экономического развития.

Причина очевидна - целью этой политики должно стать не противодействие всем видам вызовов и угроз для обеспечения состояния защищенности, а создание условий для реализации планов и программ развития страны - личности, общества и государства - в условиях действия вызовов и угроз. Таким образом, политика в области обеспечения национальной безопасности призвана гарантировать реализацию целей и задач социально-экономического развития, обеспечивая ему устойчивость в меняющемся и неспокойном мире.

Более того, изменился и сам подход к рассмотрению термина «национальная безопасность». Сегодня Стратегия национальной безопасности России выстраивает обеспечение национальной безопасности через достижение стратегических национальных приоритетов как основных направлений обеспечения национальной безопасности, оставив в прошлом сферный подход.

Одновременно формируются и новые теоретические подходы к осмыслению феномена «национальная безопасность». Например, А.И. Поздняков ввел в

\footnotetext{
${ }^{1}$ Указ Президента РФ об утверждении Концепции национальной безопасности Российской Федерации в ред. указа Президента РФ от 10.01.2000 N 24 (утратил силу).

2 Федеральный закон от 28.12.2010 N 390-Ф3 «О безопасности». Ст. 1. - Российская газета. Федеральный выпуск, № 295(5374). 29 дек. 2010 г.
} 
научный оборот понимание того, что теория национальной безопасности - это система научных положений (понятий, идей, принципов, законов, закономерностей), описывающих и объясняющих предметную область обеспечения национальной безопасности, позволяющая прогнозировать ход и исход процессов в этой области [Поздняков 2013a: 46]. Можно согласиться с этой формулировкой предметной области, т.к. она с философской точки зрения наиболее полно характеризует суть концептуальных взглядов на характер и содержание общей теории национальной безопасности.

Этот же автор ввел в научный оборот так называемый аксиологический подход, где национальная безопасность определяется как защищенность национальных ценностей, национального достояния от значимого ущерба [Поздняков 2013б]. Похожая позиция прослеживается и у ряда западных исследователей. Например, У. Липпман писал: «Государство находится в состоянии безопасности, когда ему не приходится приносить в жертву свои законные интересы с целью избежать войны и когда оно в состоянии при необходимости защитить эти интересы путем войны» [Lippman 1943: 5]. Аналогичных взглядов придерживается и А. Уолферс, который в 1962 г. отмечал, что безопасность в объективном смысле определяется отсутствием угроз приобретенным ценностям, в субъективном смысле - отсутствием боязни, что эти ценности подвергнутся нападению» [Wolfers 1962: 150].

Ряд исследователей стоят на стороне так называемого системно-философского подхода к определению национальной безопасности, который акцентирует внимание на сохранении целостности, устойчивости, стабильности страны, государства, общества как социальной системы при деструктивных воздействиях на нее.

Другие авторы, например И. Кардашова, выступают за постановку конкретных задач в области обеспечения национальной безопасности и определение конкретных путей их решения, а также за так называемый ведомственный «подход, в соответствии с которым определяются желаемые параметры национальной безопасности, разрабатывается комплекс конкретных мер для их достижения в определенные сроки» [Кардашова 2018].

Некоторые исследователи, например, О.А. Бельков, определяют национальную безопасность как состояние, тенденции развития и условия жизнедеятельности нации, гарантирующие ее выживание, свободное, независимое функционирование при сохранении фундаментальных институтов и ценностей [Бельков 2004].

Вместе с тем при всем многообразии взглядов на феномен национальной безопасности налицо явное несоответствие общепринятых сегодня теоретических воззрений на сущность национальной безопасности как состояния защищенности, с одной стороны, и стоящих перед страной и обществом целей и задач устойчивого социально-экономического развития, закрепленных в действующих документах стратегического планирования, - с другой. Понятие «состояние защищенности» неприменимо к государственной политике обеспечения национальной безопасности, построенной на принципе разумной достаточности в интересах устойчивого социально-экономического развития.

Парадигма обеспечения безопасности через «состояние защищенности» неоднократно критиковалась экспертным сообществом России как ущербная и неэффективная в современных условиях. Сегодня России необходим переход от политики обеспечения защищенности к формированию стратегии развития личности, общества, государственных институтов через выдвижение значимых и ясных стратегических целей с учетом задачи обеспечения национальной безопасности. 
Принятая же в общей теории национальной безопасности парадигма защищенности тормозит этот процесс, не предусматривает использования «мягкой силы» в интересах обеспечения национальной безопасности. Как справедливо отмечает американский автор концепции «мягкой», или «умной» силы Дж. Най, данная концепция позволяет выстраивать политику обеспечения национальной безопасности самым экономным способом: «Если ведущая держава исповедует ценности, которым хотят следовать другие, лидерство обходится ей дешевле» [Nye 2005: 5].

Кроме того, с точки зрения методологического подхода не вполне ясно, что имеется в виду под термином «защищенность»? От кого и от чего? По оценке ряда экспертов, трактовка безопасности через «состояние защищенности» беспредметна. При этом акцент делается на сооружение защиты, которую необходимо воздвигнуть, чтобы эту защищенность обеспечить, т.е. защита становится самоцелью1 ${ }^{1}$.

Такой же примерно позиции придерживается Н.Н. Рыбалкин, который считает, что «поскольку интересы и потребности можно только удовлетворять, а не защищать, то нельзя и обеспечить “состояние защищенности” потребностей и интересов» [Рыбалкин 2002: 13].

Современная политическая наука должна рассматривать сферу обеспечения национальной безопасности как сложную комплексную систему, включающую в себя ряд взаимосвязанных и взаимообусловленных подсистем: «человек гражданское общество - государственная власть - международное сообщество».

Рассматривая вопросы взаимодействия и взаимовлияния этих подсистем с позиций стратегического целеполагания и развития теории национальной безопасности, следовало бы уточнить сам подход к объекту и субъекту национальной безопасности. Как представляется, объектом национальной безопасности является объединенная единой логикой общественно-политическая, экономическая и социально-территориальная система, призванная способствовать реализации стратегических национальных приоритетов. Субъектом же национальной безопасности должно стать государство, обеспечивающее безопасность данной системы.

При таком подходе под термином «национальная безопасность» можно было бы понимать состояние общественных и государственных институтов, обеспечивающее устойчивость государственной системы по отношению к внешним и внутренним опасностям, вызовам и угрозам, реализацию государственной политики защиты национальных интересов России, а также безопасность многонационального народа России как носителя суверенитета и единственного источника власти в Российской Федерации.

Как представляется, такая трактовка центрального в теории национальной безопасности понятия учитывает уже созданные институты развития и управления, более чем 25-летний опыт государственного строительства новой России, опирается на Конституцию РФ, соотносится с проблематикой стратегического планирования и повышения эффективности деятельности различного рода государственных институтов, реализующих национальные проекты, и дает возможность более целенаправленно формировать государственную политику на этом важнейшем для страны направлении.

Изменение парадигмы «защищенность» на парадигму «состояние общественных и государственных институтов», обеспечивающее устойчивость государственной системы по отношению к внешним и внутренним опасностям, вызо-

\footnotetext{
1 Материалы V Всероссийской научно-практической конференции «Аналитика развития и безопасности России: культура, инфраструктура и интеллектуальные технологии государственного управления». Москва. Общественная палата. 15 ноября 2018 года.
} 
вам и угрозам, дает возможность уточнить стратегическое целеполагание и в других различных по масштабам и задачам концептуальных документах стратегического планирования как федерального, так регионального и отраслевого уровней. Данный подход целесообразно было бы учесть при корректировке Стратегии национальной безопасности Российской Федерации, а затем и других документов стратегического планирования в области обеспечения национальной безопасности.

При этом с точки зрения стратегического целеполагания необходимо определить, что же на сегодня и среднесрочную перспективу представляет собой важнейшие угрозы национальным интересам РФ, какие ценности являются базовыми для нашей страны в долгосрочном плане и какова должна быть стратегия защиты этих ценностей и национальных интересов, что на длительную перспективу должно явиться главным содержанием усилий государства по обеспечению национальной безопасности. Именно эти факторы имеют наиболее важное методологическое значение, поскольку непосредственно влияют на государственную политику развития страны и обеспечения национальной безопасности.

Как известно, сегодня в Стратегии национальной безопасности Российской Федерации первыми приоритетами являются оборона страны и государственная и общественная безопасность ${ }^{1}$. В последние годы многое сделано для укрепления обороноспособности страны. В настоящее время завершается выполнение текущей государственной программы вооружений на 2011-2020 гг. Ее главным результатом должно стать кардинальное обновление материальной части вооруженных сил. Доля новых образцов должна выйти на уровень 70-75\%, что приведет к серьезному росту боеспособности армии и обороноспособности страны $^{2}$. При этом поставки вооружений и военной техники в воинские части и соединения синхронизированы по времени со строительством инфраструктуры для эксплуатации оружейно-технических новинок, с подготовкой специалистов, созданием учебно-материальной базы и служебного жилья ${ }^{3}$.

Огромный объем работы, прежде всего в рамках государственной политики по борьбе с терроризмом и экстремизмом, проведен в рамках реализации стратегического национального приоритета «государственная и общественная безопасность». Такой акцент в усилиях государства и общества был продиктован оценкой угроз национальной безопасности.

Вместе с тем ранжирование стратегических национальных приоритетов, определяемых Стратегией национальной безопасности РФ, должно быть гибким инструментом, способным оперативно реагировать на новые угрозы и вызовы. Поэтому их корректировка может и должна производиться по результатам мониторинга и оценки состояния национальной безопасности, которые, в частности, отражаются в ежегодном докладе секретаря Совета безопасности президенту РФ.

Сегодня анализ состояния национальной безопасности дает серьезные основания для беспокойства. Двенадцатый год подряд наблюдается стагнация в экономике, падение реальных доходов населения, пробуксовывают реформы здравоохранения и образования. Ситуация по стратегическому национальному приоритету «качество жизни» неудовлетворительна. Опросы показывают рост

\footnotetext{
1 Указ Президента Российской Федерации от 31.12.2015 N 683.

2 Перевооружение российской армии. Получено и ожидается: поставки техники в 2019 году. Военное обозрение. 11.06.2019. Доступ: https://topwar.ru/160013-polucheno-i-ozhidaetsja-postavkivooruzhenij-i-tehniki-v-2019-godu.html (проверено 21.01.2020).

3 Выступление министра обороны России С. Шойгу на заседании коллегии Министерства обороны. - Российская газета. 07.11.2017.
} 
недоверия к институтам власти, пессимизма в оценке гражданами перспектив своего материального положения.

По оценке экспертов центра конъюнктурных исследований Высшей школы экономики, индекс потребительской уверенности граждан по итогам III квартала 2019 г. остается в зоне отрицательных значений (-13\%), что говорит о низкой удовлетворенности граждан текущими стандартами уровня и качества своей жизни. 40\% граждан России считают, что экономика страны за последний год ухудшилась. При этом каждый четвертый россиянин фиксирует ухудшение своего материального положения ${ }^{1}$.

По данным совместного исследования Московского центра Карнеги и Левада-Центра, доля россиян, выступающих за решительные перемены в стране, выросла за 2 года с 42\% до 59\%. 53\% респондентов считают, что такие перемены возможны лишь при условии серьезного изменения политической системы $^{2}$.

Сохраняются системные проблемы в российской науке, которая еще не стала движущей силой реформ. Госсектор в экономике все растет, а эффективность экономических процессов снижается. Гражданское общество все больше расслаивается. Единый день голосования в текущем году сопровождался ростом протестной активности, которая, по оценке многих депутатов Госдумы, подогревалась извне ${ }^{3}$.

Отмеченные негативные тенденции указывают на то, что в новой редакции Стратегии национальной безопасности следует уделить больше внимания таким стратегическим национальным приоритетам, как качество жизни и экономический рост. Принцип «безопасность через устойчивое развитие», лежащий в основе современных взглядов на обеспечение национальной безопасности, подразумевает комплексный подход к задачам укрепления обороны, государственного суверенитета, независимости и конституционного строя, который включает в себя опережающее развитие экономики, рост благосостояния граждан, сокращение социального неравенства, укрепление внутриполитической стабильности, межнационального и межконфессионального согласия. Эти долгосрочные задачи составляют главное содержание посланий президента РФ Федеральному собранию РФ последних лет.

Как представляется, с точки зрения уточнения стратегических национальных приоритетов, которые являются главным содержанием Стратегии национальной безопасности Российской Федерации, ключевое значение имеет задача «сбережения» российского народа, поставленная В.В. Путиным в послании ФС РФ 2019 г. $^{4}$

Эти поручения президента РФ следовало бы отразить при корректировке Стратегии национальной безопасности (далее - Стратегия), обеспечив тесную увязку задач социально-экономического развития, здравоохранения, науки, образования и культуры с потребностями обеспечения национальной безопасности.

Методология такой корректировки могла бы представлять собой последовательную итерационную схему стратегического анализа и стратегического прогнозирования по каждому стратегическому национальному приоритету с формированием обобщенных оценок состояния национальной безопасности в

\footnotetext{
1 Граждане погрузились в потребительский пессимизм. - Независимая газета. 15.10.2019.

2 Почти 60\% россиян выступают за решительные перемены в стране. - Ведомости. 06.11.2019.

3 Госдума включится в борьбу с «иностранным вмешательством» в выборы. - Ведомости. 8.08.2019.

4 Послание Президента РФ Федеральному Собранию от 20.02.2019. Доступ: http://www. consultant.ru/document/cons_doc_LAW_318543/ (проверено 21.01.2020).
} 
соответствии с Перечнем показателей состояния национальной безопасности, введенным в действие указом президента одновременно с действующей редакцией Стратегии. Важно, чтобы в этой работе участвовали представители всех звеньев исполнительной власти, что поможет обеспечить единое понимание, а затем и реализацию приоритетов развития страны и обеспечения ее безопасности.

Результаты корректировки Стратегии после ее утверждения должны учитываться во всех документах стратегического планирования, в т.ч. в госпрограммах и бюджетном планировании, в соответствии с базовым принципом, отраженным в Стратегии национальной безопасности России и закрепленным в законе о стратегическом планировании № 172-Ф3, о неразрывной взаимосвязи и взаимозависимости социально-экономического развития страны и обеспечения национальной безопасности.

Получивший в отечественной политической практике название «безопасность через устойчивое развитие» [Назаров 2013], этот принцип предполагает, что только такая взаимосвязь обеспечивает надежное достижение стратегических национальных приоритетов, позволяет выстраивать государственную политику обеспечения национальной безопасности на принципах стратегического планирования наиболее эффективным и рациональным способом, обеспечить динамичное социально-экономическое развитие страны, устойчивое к вызовам и угрозам национальной безопасности. Последовательное соблюдение этого принципа призвано гарантировать разумную достаточность ресурсов, выделяемых на обеспечение национальной безопасности, не допуская их избыточности в ущерб интересам развития.

И наконец, в новой редакции Стратегии национальной безопасности следует четко определить составные части национальной безопасности как общественно-политического явления. Такая необходимость вызвана тем, что сегодня в научный оборот и политическую практику нередко вводятся понятия миграционной, демографической, психологической безопасности, финансовой, гуманитарной и кибербезопасности и целого ряда иных «безопасностей», которые их авторы пытаются рассматривать в контексте понятия «национальная безопасность».

Безусловно, каждая предметная область может охватывать вопросы безопасности - обеспечение безопасности при производстве любых работ, в той или иной сфере деятельности и т.п. Однако применительно к понятию «национальная безопасность» целесообразно придерживаться принципа: один стратегический национальный приоритет - одно направление обеспечения безопасности плюс информационная безопасность, которая обеспечивает реализацию каждого стратегического национального приоритета. В таком случае мы получаем достаточно ограниченный набор отраслей национальной безопасности - это военная, международная, государственная и общественная, экономическая, экологическая, демографическая и информационная безопасность.

Из сказанного выше можно сделать следующие выводы.

Теория национальной безопасности имеет не только теоретическое измерение. Научные построения и новации в этой области могут внести серьезный вклад в дело совершенствования государственного управления. Последовательное обеспечение единства системы стратегического планирования и государственного управления на основе строгого соблюдения принципа «безопасность через развитие» способно качественно повысить эффективность государственной политики, деятельности органов власти и гражданского общества по строительству современного и динамично развивающегося общества, отвечающего вызовам быстро меняющегося мира, обеспечить необходимый уровень социального 
согласия и политической стабильности и внести существенный вклад в международную безопасность.

\section{Список литературы}

Бельков О.А. 2004. Понятийно-категориальный аппарат концепции национальной безопасности. - Безопасность: информационный сборник. № 3. C. 91-94.

Возжеников Л.В. 2000. Парадигма национальной безопасности реформирующейся России. М.: ЭДАС ПАК. 358 с.

Кардашова И.Б. 2018. Основы теории национальной безопасности: учебник для вузов. М.: Юрайт. 303 с.

Манилов В.Л. 1995. Теория и практика организации системы обеспечения национальной безопасности России: автореф. дис. ... д.полит.н. М. 52 с.

Назаров В.П. 2013. Стратегическое планирование как важнейший фактор повышения эффективности государственного управления. - Власть. № 12 . C. 4-11.

Общая теория национальной безопасности: учебник (под общ. ред. А.А. Прохожева). 2005. М.: Изд-во РАГС. 344 с.

Поздняков А.И. 2013а. Сравнительный анализ основных методологических подходов к построению теории национальной безопасности. - Национальные интересы: приоритеты и безопасность. № 21(210). С. 46-53.

Поздняков А.И. 2013б. Концептуальные основы национальной безопасности России. - Основы теории национальной безопасности: курс лекций. Лекция 1. Электронное научное издание Альманах Пространство и Время. Т. 2. Вып. 1. C. 1-17. Доступ: https://cyberleninka.ru/article/n/osnovy-teorii-natsionalnoybezopasnosti-kurs-lektsiy-lektsiya-1-kontseptualnye-osnovy-natsionalnoybezopasnosti-rossii/viewer (проверено 21.01.2020).

Рыбалкин Н.Н. 2002. Философия безопасности. М.: ОЛМА-ПРЕСС. 252 с.

Сергунин А.А. 2012. Концепт «военная безопасность» и эволюция военнополитического мышления постсоветской России. - Bопросы безопасности. № 2. C. 119-140.

Lippman W. 1943. US Foreign Policy: Shield of the Republic. Boston: Little, Brown and Co. XIV, $177 \mathrm{p}$.

Nye J.S., Jr. 2005. Soft Power: The Means to Success in World Politics. .N.Y.: Public Affairs, $191 \mathrm{p}$.

Wolfers A. 1962. Discord and Collaboration: Essays on International Politics. Baltimore: The Johns Hopkins University Press. XVII, 283 p. 
NAZAROV Vladimir Pavlovich, Cand.Sci. (Pol.Sci.), Adviser to the Secretary of the Security Council of the Russian Federation (103132, Russia, Moscow, Ipat'evsky Lane, 4-10; Vlnazarov1950@gmail.com)

AFINOGENOV Dmitry Aleksandrovich, Dr.Sci. (Pol.Sci.), Professor at the Institute of Law and National Security, Russian Presidential Academy of National Economy and Public Administration (RANEPA) (bld. 6, 84 Vernadskogo Ave, Moscow, Russia, 119571; afinogenov_d@inbox.ru)

\title{
PROBLEMS OF DEVELOPMENT OF THE GENERAL THEORY OF NATIONAL SECURITY IN THE CONTEXT OF ADJUSTMENT OF NATIONAL SECURITY STRATEGY OF THE RUSSIAN FEDERATION
}

\begin{abstract}
The article discusses the development of the Russian Federation's national security theory in the new geopolitical and economic environment. The authors present substantive analysis of the change in theoretical views on the concept of national security and propose a new approach to the content of the term. The article justifies the role and the place of strategic planning as an essential tool for national security and gives recommendations for optimization and improvement of this process as well as for updating the National Security Strategy of the Russian Federation.

Keywords: national security, social-economic development, strategic planning, strategic national priorities, goal setting, strategy
\end{abstract}

БЕЛОЗЁРОВ Василий Клавдиевич - доктор политических наук, профессор, заведующий кафедрой политологии Московского государственного лингвистического университета; член научного совета при Совете безопасности РФ; сопредседатель Ассоциации военных политологов (119034, Россия, г. Москва, ул. Остоженка, 38; vk_belozerov@таil.ru)

\section{ДЕФИЦИТ СТРАТЕГИЧЕСКОГО МЫШЛЕНИЯ И ИМПЕРАТИВЫ ЕГО ПРЕОДОЛЕНИЯ. РАЗМЫШЛЕНИЯ ПОСЛЕ ВЕНСКОЙ КОНФЕРЕНЦИИ ПО СТРАТЕГИИ}

Аннотация. В статье по результатам осмысления Венской конференции по стратегии констатируется возникновение запроса на стратегическое мышление, который артикулируется как в Европе, так и в России. Образовавшийся дефицит стратегического мышления негативно влияет на обеспечение глобальной, региональной и национальной безопасности. Автор обосновывает позицию, что указанный дефицит может и должен быть преодолен при определенных условиях. В данном контексте императивный характер носит налаживание устойчивого взаимодействия с зарубежным экспертным сообществом. Ключевые слова: Венская конференция по стратегии, стратегическое мышление, государственная стратегия, экспертное сообщество, восприятие России в мире, преодоление дефицита стратегического мышления

$\mathrm{B}$ конце июня 2019 г. в Академии национальной обороны Австрии состоялась вот уже четвертая ежегодная Венская конференция по стратегии (Wiener Strategiekonferenz). Мероприятие вновь осталось незамеченным для российской научной общественности. Между тем, имеется целый ряд обстоятельств, свидетельствующих в пользу того, что конференция заслуживает внимания, в т.ч. в связи с приданием импульса исследованиям стратегии и стратегического мышления в России. 